EESTI NSV TEADUSTE AKADEEMIA TOIMETISED. GEOLOOGIA

ИЗВЕСТИЯ АКАДЕМИИ НАУК ЭСТОНСКОП ССР. ГЕОЛОГИЯ

PROCEEDINGS OF THE ACADEMY OF SCIENCES OF THE ESTONIAN SSR. GEOLOGY

1984, 33, 1

удК $551.243 .001: 552.6(474.2)$

Э. КАЛА, В. ПУУРА, К. СУУРОЯ

\title{
ГЛАВНЫЕ ЧЕРТЫ СТРОЕНИЯ КЯРДЛАСКОГО ПОГРЕБЕННОГО КРАТЕРА
}

История выявления Кярдлаского кратера началась в 1967 г., когда были обнаружены (при бурении артезианской скважины в Палукюла) кристаллические породы на глубине всего 22 м вместо ожидаемых более чем в 200 м. Это побудило Институт геологии АН ЭССР, а также (в ходе геологической съемки) Управление геологии ЭССР к проведению буровых работ. Первоначально поднятия кристаллических пород в Палукюла и Тубала считали ядрами платформенных складок (плакантиклиналей), а время их формирования - ранний ордовик (Viiding и др., 1969). По результатам детального изучения кембрийских отложений в керне скв. 1 Э. Пиррус (Институт геологии) конкретно показал послелюкатиское (после-раннекембрийское) время процессов формирования поднятия Палукюла, обратив внимание на дислокацию описанных отложений (Pirrus, 1976).

В 1972-1981 гг. Управлением геологии ЭССР проводились буровые, геофизические и гидрогеологические работы в связи с поисками в поднятиях кристаллического фундамента пород, пригодных для изготовления высокопрочного щебня, и с целью составления сводной геологической карты.

Само существование кратера в северо-восточной части о. Хийумаа, у южной окраины Кярдла, выяснилось в 1972 г. в результате крупномасштабных геофизических съемок. Известные поднятия фундамента Палукюла, Тубала и др. оказались в пределах кольцевой пюложительной аномалии, а обнаруженное при бурении понижение в рельефе фундамента - в контуре центрального минимума (Пуура, 1974; Кала и др., 1978; Гайлюс и др., 1978). Сведения о Кярдласком кратере заинтересовали опециалистов, изучающих космогенные структуры (Геология астроблем, 1980; Импактиты, 1981).

Ныне Кярдлаский кратер изучен на основании более чем 100 буровых скважин, из которых 55 были проведены до кристаллических пород. Все же северная и южная части кольцевого вала, а также внутренняя глубокая часть и окружение кратера изучены слабо. Перед тем как приступить к описанию Кярдлаского кратера - уникального геологического объекта в Эстонии - следует отметить, что по мере продвижения исследований авторы данной статьи все более убеждались в его ударно-взрывном (импактном) происхождении и в том, что этот взрыв произошел в конце кукрузеского - начале идавереского времени (средний ордовик).

Кярдлаский кратер (кольцевая структура, диаметр 4 км) находится в северо-восточной части о. Хийумаа, у юго-восточной границы районного центра Кярдла (рис. 1). Этот остров расположен в северозападной части субширотной Западно-Эстонской моноклинали региональной платформенной структуры на южном склоне Балтий-

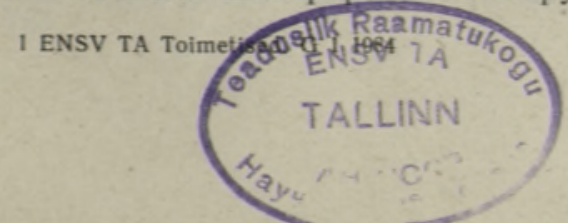


ского щита (Тектоника Прибалтики, 1979). Осадочный чехол общей мощностью около 240 м в данном районе сложен кембрийскими терригенными $(\sim 130$ м) и ордовикскими, преимущественно карбонатными ( 100 м), осадочными породами, маломощным (0-20 м) покровом четвертичных отложений и наклонен в южном - юго-восточном направлении (азимут $165^{\circ}$ ) около $10-14^{\prime}$ (3-4 м/км).

Кристаллический фундамент района представлен архейским комплексом мигматизированных метаморфических пород амфиболитовой фации метаморфизма. Складчатые структуры фундамента имеют, судя по магнитным аномалиям, изменчивое (в восточной части в основном северо-западное) направление. Сама Кярдлаская структура обозначена округлым магнитным и травитационным минимумами, соответствующими внутренней впадине, и кольцевым максимумом над окружающим валом (рис. $2 A, Б$ ). Локальные гравитационные аномалии (интенсивностью до $\pm 2,5$ мГл) на общем фоне мозаичных аномалий прекрасно коррелируются со структурными элементами кратера (рис. 2Б). Гравитационные аномалии выражены более ярко, чем магнитные, что в общем согласуется с особенностями петрофизических свойств пород фундамента и чехла.

В региональных геофизических аномалиях слабо проявлена линейная зона, имеющая северо-восточное простирание и пересекающая Кярдласкую структуру. Однако, по данным детальных геофизических съемок и геологических исследований, выделение такого разлома по-прежнему проблематично. Небезынтересно и то, что недавно А. Мардла в результате интерпретации космических фотографий обнаружил кольцевой объект, несколько эксцентричный по отношению К Кярдласкому кратеру (рис. 1).

В геологической праќтике структуру Кярдлаского кратера обычно описывали по маркантной поверхности пород кристаллического фундамента (как монолитных, так и разрушенных, рис. 3), которую ныне следует считать разновозрастной и тенетически разнородной. За пределами кратера это докембрийская выравненная поверхность пород архейского фундамента, на внешнем склоне кольцевого вала - условная траница преобладания кристаллических пород над разрушенными породами чехла, на гребне вала - іденудационная поверхность, выработанная перед началом формирования перекрывающего комплекса, а внутри кратера - условная верхняя граница грубообломочных брекчий пород кристаллического фундамента. Внутри кратера описываемая граница пока практически не изучена и проведена орнентировочно с учетом геофизических данных. Вершина пребня вала кристаллических пород в Палукюла находится выше обычного уровня поверхности фундамента на 240 и выше дна кратера почти на 500 м. Однако, если принять за точку отсчета поверхности мишени уровень кровли кукрузеского горизонта в восточном обрамлении кратера, то истинная высота вала кратера в районе Палукюла достигнет только 100 , а. мощность интенсивно деформированных и в большей части выброшенных из кратера пород (исходная глубина кратера) не менее $400-500$ м.

Мишенью для взрыва в геологическом разрезе послужили (сверху вниз): карбонатные породы кукрузеского, ухакуского, ласнамягиского, азериского (средний ордовик), кундаского и волховского (нижний ордовик) горизонтов общей мощностью 10-12 м, керогенсодержащие граптолитовые аргиллиты (диктионемовые сланцы) мощностью около 1 м, оболовые песчаники пакерортского горизонта (нижний ордовик) мощностью 6-7 м, а также песчаники и алевролиты, перемежающиеся с алевритовыми глинами нижнего кембрия мощностью около 130 м. Общая мощность нарушенного при взрыве осадочного комп- 
лекса около 150 м. Далее следуют породы кристаллического фундамента с корой выветривания в верхней части, в которые кратер углубился еще на 250-350 м.

В обрамлении Кярдлаского кратера нижнекембрийские, а также нижне- и среднеордовикские осадочные толщи дислоцированы под влиянием взрыва, образовавшего сам кратер. В разрезе (рис. 4) заметно, что они приподняты вблизи вала. На некоторых участках раздробленные доимпактные осадочные толщи входят в строение вала.

Послеимпактные средне- и верхнеордовикские карбонатные толщи за пределами кратера, в некотором отдалении от вала, имеют пологий наклон, как и общая моноклинальная структура. Вблизи вала, в его внешнем обрамлении, заметно значительное угловое несогласие между до- и послеимпактными толщами. Главная особенность залегания послеимпактных толщ - их складкообразное поднятие над валом и глубокое попружение внутри кратера. Например, подошва идавереского горизонта в обрамлении структуры находится в пределах абсолютных отметок -90, а внутри кратера ниже -270 м (разница 180 м). Подошва набалаского горизонта за пределами кратера (на опметках около - 30 м) подымается на пребне вала в Палукюла до +20 , а в центре кратера опускается ниже -100 м (рис. $5 A$ ). Разница、в абсолютных отметках структурных поверхностей внутри послеимпактной толщи уменьшается снизу вверх ввиду того, что мощность горизонтов уменьшена на вале и заметно увеличена внутри кратера.

В начальных стадиях изучения структуры приподнятость послеимпактных осадочных толщ на вале и существенное опускание их внутри кратера воспринималось авторами статьи как явное свидетельство о постумных тектонических движениях - поднятии вала и опускании дна кратера. Однако признание взрывной, возможно, метеоритной природы кратера заставляет проанализировать также альтернативные объяснения этих особенностей: осадконакопление при неровном рельефе дна (о чем свидетельствуют выклинивание базальных комплексов на гребне вала и увеличение их мощности в кратере) и относительное постседиментационное опускание во внешнем обрамлении вала и особенно в кратере за счет диагенетического уплотнения рыхлых осадков в течение геологического времени. Максимальные наклоны слоев на скатах вала, рассчитанные по данным буровых скважин, составляют (по подошве набалаского горизонта) на внешнем скате 25 и на внутреннем $15-20^{\circ}$. Это в общем согласуется с замеренными в обнажениях и непосредственно по керну́ максимальными значениями наклона от 10 до $20^{\circ}$. Наклонное залегание слоев, вероятно, свидетельствует о постседиментационном опускании толщ за пределами вала. Все же затронутые вопросы становления структуры осадочных толщ заслуживают пристального внимания, если учесть также фациальные особенности отложений.

Строение кольцевого вала, его состав, высота и ширина на всем его протяжении сильно варьируют. Это, очевидно, объясняется различными соотношениями кристаллических и осадочных пород в образовавшемся при взрыве вале. Это обстоятельство повлияло на степень устойчивости разных участков вала в процессах денудации перед накоплением перекрывающего комплекса и в начале его, а также, очевидно, вызвало колебания конечных параметров (высота, ширина) вала. Во всяком случае, в наивысших точках (при абсолютных отметках поверхности +8,4 м в Палукюла и -21,5 м в Тубала) вал сложен одними кристаллическими породами и только в его седловинах на вершине есть осадочные породы (кембрийские отложения на уровне - 62 м в скважине Лыппе 414 и на уровне -75 м в скважине Тубала $\Phi-176)$. 
На участке Палукюла, где кольцевой вал состоит почти из одних кристаллических пород (Палукюлаское поднятие), он изучен, с целью поисков гранита. На этом участке пробурили 45 скважин, из них несколько глубоких (скважина Ф-241 максимальной тлубины 248 м, в том числе по кристаллическим породам 222, (м́) вплоть до обычного уровня поверхности кристаллического фундамента. Это позволило заключить, что вал состоит из крупных блоков пород кристаллического фундамента, разбитых трещинами, заполненными продуктами дробления тех же пород или эпигенетическими карбонатными минераламн (кальцитом, реже доломитом) и сульфидами (пиритом, реже галенитом и сфалеритом), изредка даже асфальтитом (рис. 4). По гипсометрическому положению это сооружение замещает осадочные породы исходного разреза и возвышается над их поверхностью, как указано выше, до 100 м. Генетически его можно объяснить как аутигенную брекчию, перемещенную от центра кратера к его периферии и вверх максимально на сотни метров.

Подобное этому, но меньшее по амплитуде перемещение, очевидно, претерпели также доимпактные породы фундамента и осадочного чехла, с внешней стороны примыкающие к валу. Если ширина вала кристаллических пород в Палукюла около 500-600 м, то ширина зоны дислокации с внешней стороны вала достигает 1,5 км. Таким образом, общий диаметр круга (или овала) нарушенных пород, вероятно, достигает $6,5-8$ км.

Однако зона дислокаций внешнего обрамления кольцевого вала проявляется в погребенном доимпактном комплексе пород. На уровне современного эрозионного среза коренных пород сказывается только влияние кольцевого вала и внутренней впадины. Как следует из сопоставления схем коренного рельефа (рис. 55 ) и геологического строения (рис. 1), в формировании черты выходов горизонтов структура явно превалирует над рельефом. На поверхность вала кратера, несмотря на максимальные абсолютные отметки рельефа коренных пород $(+23$ м), выходят наиболее древние отложения (паэкнаская свита набалаского горизонта), а внутри кратера в понижении рельефа (<-10 м) - самые молодые - юуруский горизонт нижнего силура.

Рельеф коренных пород весьма полно отражает их структуру: морфологически выражены Палукюлаское и Тубалаское поднятия, внутренняя впадина (кратер) и др. элементы. Одновременно часть форм рельефа ответвляется от кратера без явной структурной обусловленности (возвышенность в районе Партси - Паладе), что может быть объяснено, например, друмлинизацией коренного рельефа в ледниковую эпоху.

Вообще, судя по палеогеоморфологическим реконструкциям, в районе кратера за дочетвертичный континентальный период и в ледниковое время уничтожены значительные мощности силурийских н, возможно, более молодых осадочных пород. Близповерхностно погребенный и почти полностью сохранившийся (сохранились окружной вал и закратерные выбросы) Кярдлаский кратер - благоприятный исход событий в геологическом прошлом, благодаря которому это уникальное сооружение законсервировано в таком удобном для изучения положении.

Для характеристики некоторых структурных особенностей кратера и позиции отдельных сформированных при взрыве специфических комплексов пород удобно пользоваться классификацией структурнолитологических комплексов астроблем, предложенной В. Л. Масайтисом (Масайтис, 1977) и другими. По этой классификации в строении Кярдлаского кратера могут быть выделены: 1) цокольный, 2) коптогенный, 3) заполняющий и 4) перекрывающий комплексы. 


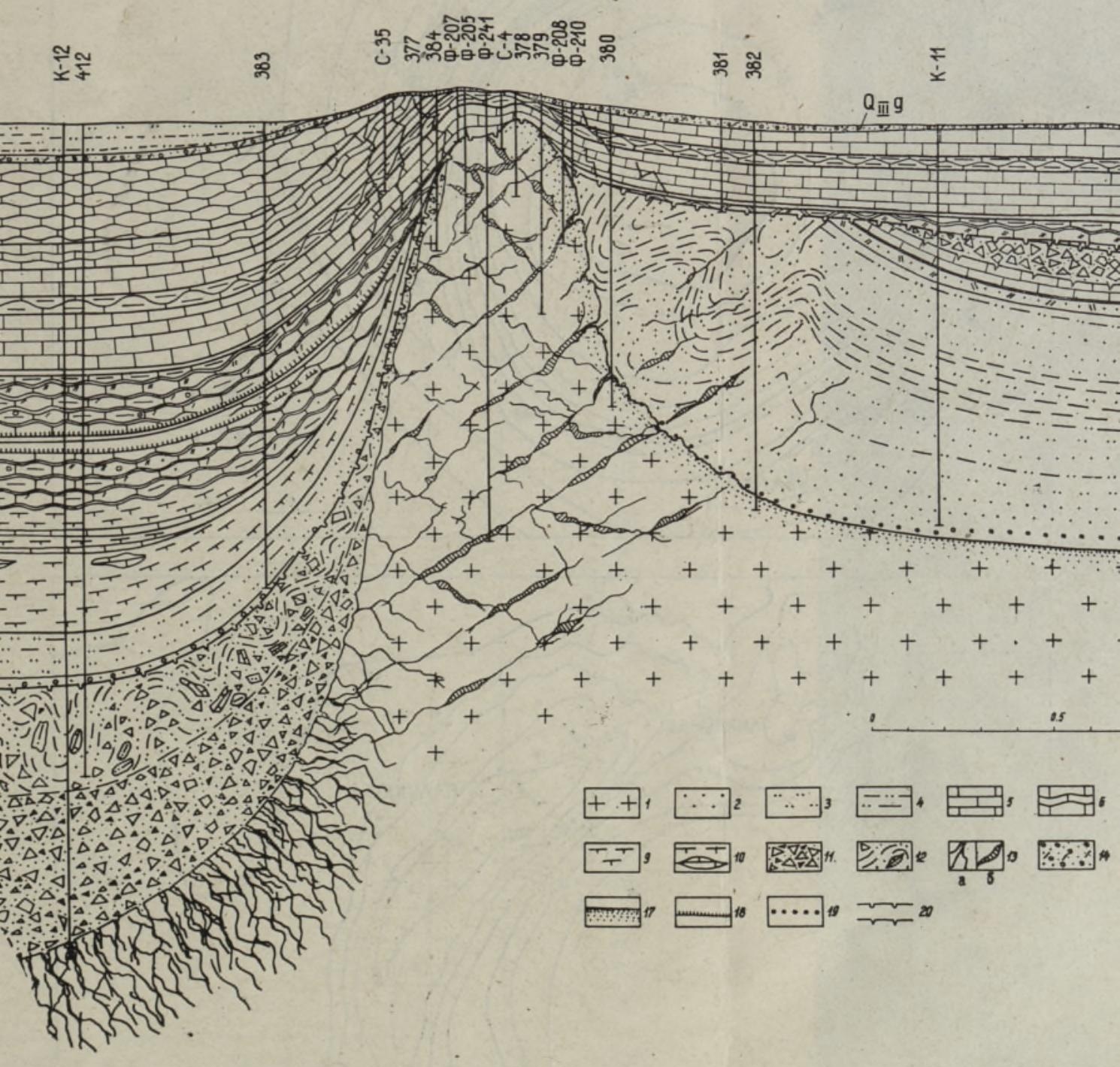

разрез северо-восточной части Кярдлаского кратера. 1 - крнсталлические породы (граннты, гнейсы, ам иты и алевриты, 4 - алеврнтовые глины, 5-8 - нзвестнякн: афанитовые (5), волнисто-слонстые (6), к ргеля (8); 9 - мергели, 10 - мергели с комками известняка, 11 - взрывные брекчни, 12 - конгл ментированного обломочного материала (б), 14 - морена, 15 - детрнтовый песчаник, 16 - слой ди ния кристаллических пород, 18 - слон метабентонита, 19 - галька кристаллических пород, 20 - п 

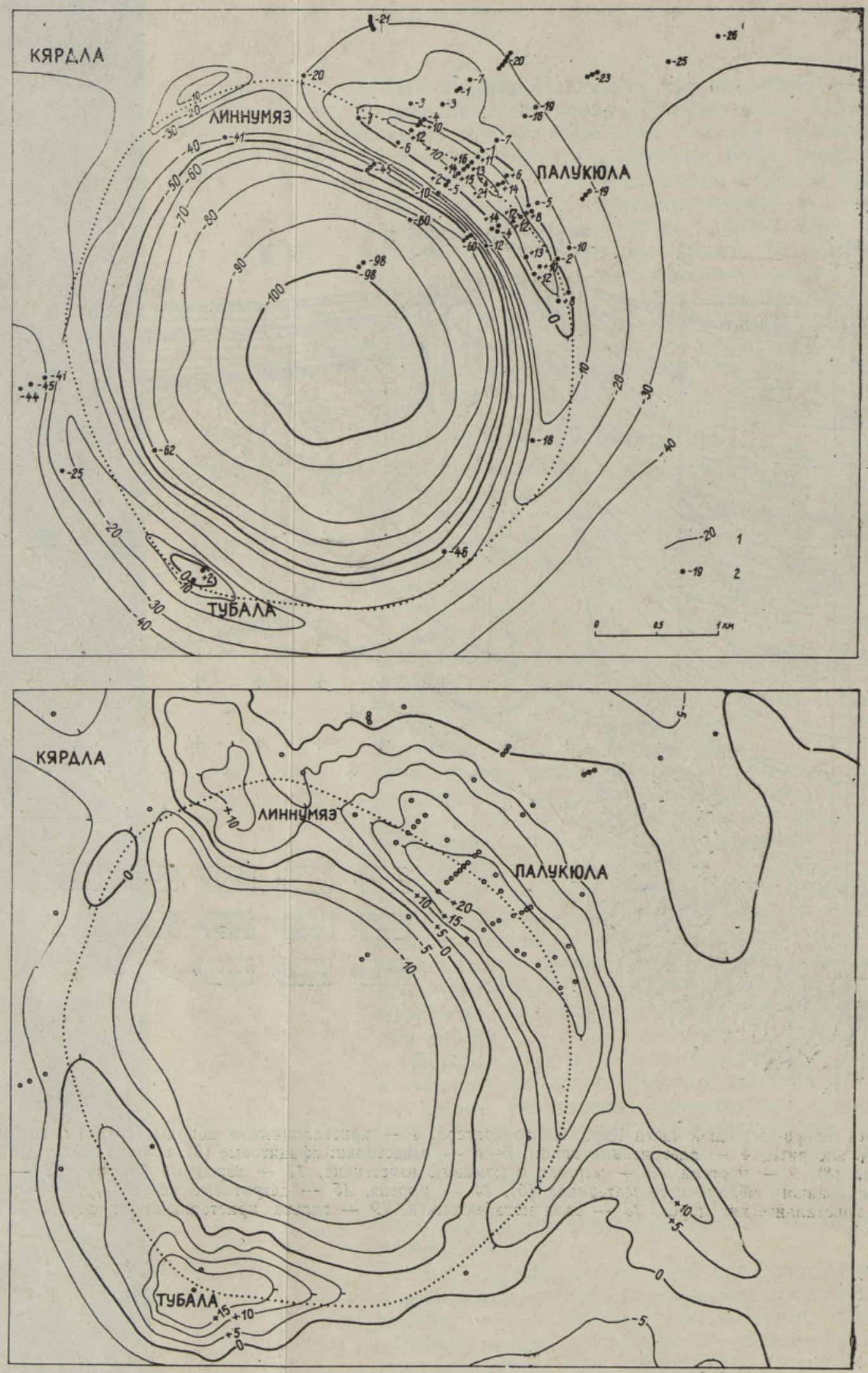

Рнс. 5. Структурная схема перекрывающего комплекса по подошве набалаского горизонта и схема рельефа коренных пород. Линиями обозначены изогипсы через $10(A)$ и 5 м $(D)$; цифрами у буровых скважин $(A)$ - абсолютные отметки подошвы набалаского горизонта; точечной линией - гребень кольцевого вала. 

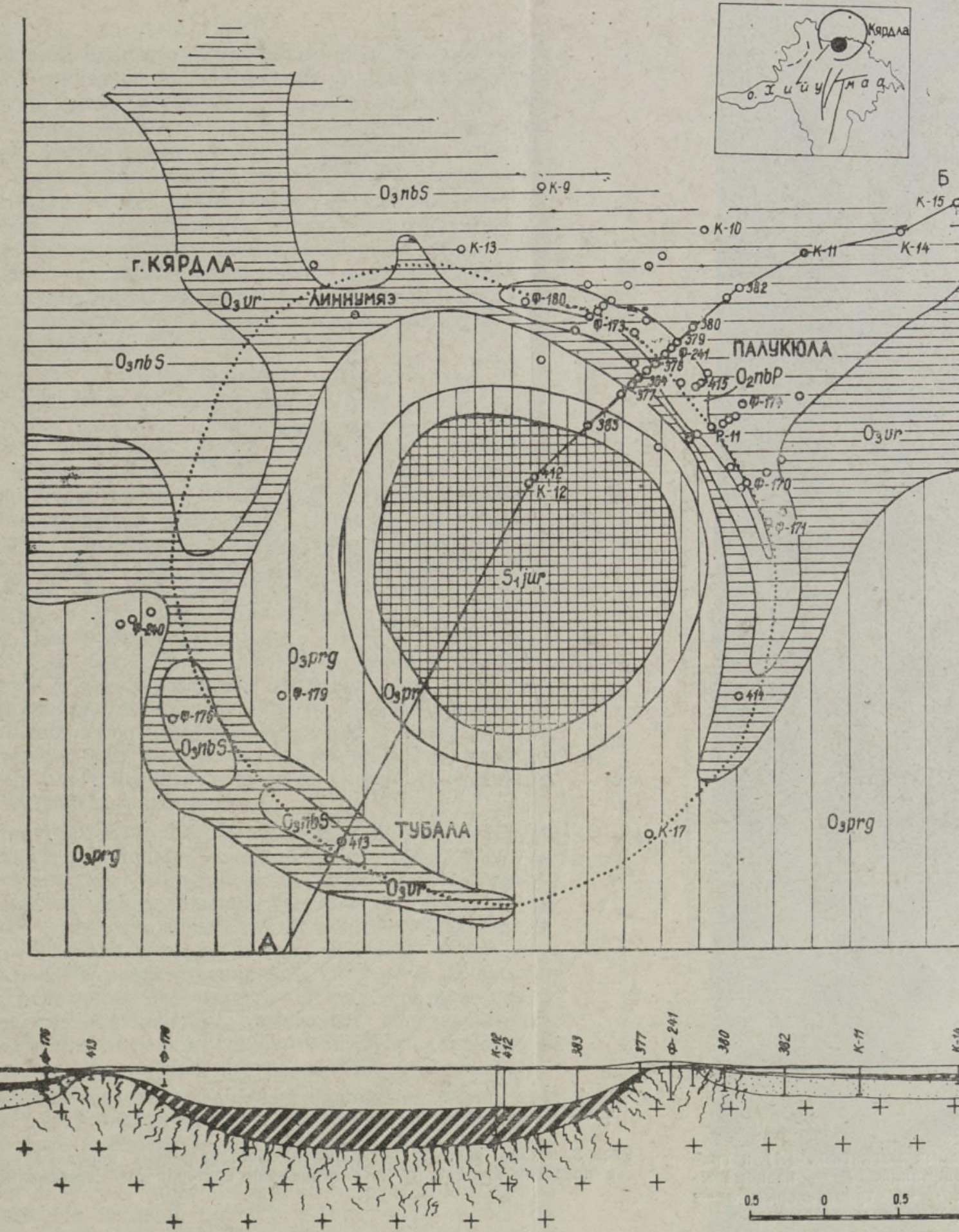

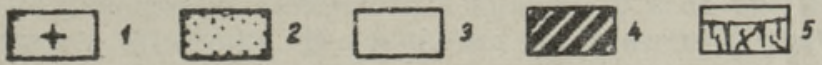

Схема расположения и строения Кярдлаского кратера. На врезке показаны кольцевой и линейные эл е А. Мардла при дешифровке космической фотографии. На геологической карте-схеме штриховкой выхода; индексами - возраст стратиграфических единиц; точечной линией - гребень кольцевого - местоположение буровых скважин (цифрами выборочно их номера). 1 - породы кристаллическ 2 - терригенные и глинистые породы нижнего кембрия и нижнего ордовика; 3 - карбонатн) а и нижнего силура; 4 - брекчин, конгломераты и другие слабосортированные образования; 5 ватость открытая и закрытая. 
Цокольный комплекс объединяет доимпактные породы осадочного чехла (до кукрузеского горизонта включительно) и кристаллическөго фундамента, в частности также аутигенные брекчии на дне кратера и в кольцевом вале, - раздробленные породы в первичном или близком к тому залегании. Коптогенный комплекс представлен аллогенной брекчией тех же пород, заполняющей дно кратера и перекрывающей вал (образуя насыпь), и даже примыкающие к валу закратерные пространства (выбросы). К заполняющему комплексу относятся заметно отсортированные и в различной степени окатанные территенные образования (алевролиты, песчаники, гравелиты, конгломераты) на дне и склонах кратера, представляющие собой, в основном, переотложенные в водной ореде продукты разрушения коптогенного, возможно, отчасти и цокольното комплексов.

В кратере коптогенный комплекс большой мощности (скв. К-12, интервал $301-459+$ м) представлен аутигенной брекчией глыб, щебня и дресвы кристаллических пород и терригенного материала осадочного чехла. На гребне окружного вала. в локальных ложбинках рельефа (их глибина в скв. Р-11 3 м, Ф-241 1 м), как и на седловинах (скв. Ф-180 мощностью свыше 38 м), наблюдается насыпь аллогенная брекчия коптогенного комплекса. Остается впечатление, что насыпные коптотенные образования с пребня вала в основном денудированы. С внешней стороны вала коптотенные обпазования (закратерные выбросы), помимо крупных тлыб (скв. К-15, диаметр глыбы фундамента свыше 22 м), в виде маломошного слоя развиты в обрамлении на протяжении 1 км и более (скв. $\mathrm{K}-14-16.4$ м. K-15 и K-16 в Палукюла, см. рис. 4, а также в скв. Ф-176 Тубала) и представлены обломками пород кристаллического финдамента и осадочного чехла (идентифицированы обломки пород вплоть до кикрузеского гопизонта среднего ордовика включительно). Восточнее Палукюла (скв. K-15, K-16) эта аллогенная брекчия накладывается на зону своеобразной аутигенной брекчии известняков кукрузеского горизонта, очевидно, образовавшуюся под влиянием ударной волны.

На брекчиях коптогенното комплекса в кратере и за его пределами залегают образовавшиеся в подвижной водной среде терригенные тороды заполняющего комплекса: конгломераты, правелиты, песчаники и алевролиты - продукты переотложения рыхлого матепиала кольцевого вала. Мощность этих отложений кратера в скв. К-12 28,4 м, а их возрастных и генетических аналогов во внешнем обрамлении вала в скв. К-14; K-15; K-16 соответственно 2,9; 5,9; 13,2 м. Поскольку на груботерригенные отложения внутреннего склона кратера накладываются разновозрастные карбонатные отложения перекрывающего комплекса (от идавереского до раквереского горизонта), необходимо допустить разновременное в различных местах образование первых.

Принимая во внимание стратиграфическое положение аутигенных брекчий карбонатных пород (верхи кукрузеского горизонта), на которых залегают закратерные выбросы, время образования кратера устанавливают однозначно. К тому же палеонтологическими исследованиями Р. М. Мянниля в 1971 г. доказана принадлежность к идаверескому торизонту аномально мощной (до 106 м. скв. 412) толщи базальных карбонатных отложений перекрывающего комплекса внутри кратера. Менее выражено увеличение мощности в кратере у всех последующих горизонтов среднего ордовика. В зависимости от высоты вала он 'перекрывался разновозрастными отложениями - от идавереского до раквереского горизонтов. На участке Палукюла, где высота вала максимальная, все горизонты среднего ордовика, кроме раквереского и набалаского, выклиниваются, а на участках низкого вала разрез начинается с идавереското горизонта, но имеет, как и на всем вале, 
пониженную мощность. В соответствии с распределением мощности и очевидным изменением глубины бассейна (ввиду его неровного дна) замечены изменения фациального характера отложений. Например, кейлаский горизонт у Палукюла на гребне вала представлен грубодетритовыми цистоидными известняками, а на некотором удалении от него (около 500 м) в сторону кратера и внешнего склона - комковатыми глинистыми известняками и мергелями. Фациальная изменчивость отложений в зависимости от структурных условий в районе кратера заслуживает дальнейшего тщательного изучения.

В заключение следует указать, что о происхождении Кярдлаского кратера нет прямых сведений и поныне, так как не найдено вещественных доказательств метеоритной или вулканической природы. Ранее авторы придерживались эндогенной гипотезы взрывного происхождения Кярдлаского кратера, объясняя это его размещением в зоне предполагаемого разлома северо-восточного простирания и особенно различным гипсометрическим положением перекрывающих карбонатных отложений за пределами кратера, над его валом и внутри кратера (свидетельство о постумных, в том числе постордовикских тектонических движениях). Такое предположение заслуживает дальнейшего пристального внимания.

С другой стороны, нельзя отрицать очевидного сходства Кярдлаского кратера с метеоритным. Соотношение тлубины и диаметра Кярдлаского кратера 0,5 км : 4 км $\approx 0,12$. По данным зарубежных и советоких авторов, величина этого соотношения для мелких метеоритных кратеров (диаметром $n \times 100$ м) $0,25-0,33$, а при увеличении диаметра $(n \times 10 \mathrm{kм})$ уменьшается до $0,02-0,03$. Для вулканических кратеров это соотношение обычно не менее $0,34-0,42$, различна также их морфология (Импактиты, 1982, с. 59). Аномальные геофизические поля над Кярдласким кратером сближают его с метеоритными, а не с вулканическими образованиями.

В изучении Кярдлаского кратера сделаны лишь первые шаги. Для более полного исследования его строения, вещественного состава структурно-литологических комплексов и, наконец, генезиса и истории формирования необходимо дополнительное бурение и более детальное обследование уже существующего кернового материала. Этому способствует и лучшая сохранность Кярдлаского (особенно его кольцевого вала) среди других палеозойских и более древних кратеров (Импактиты, 1981, с. 192-205).

С точки зрения дальнейшего познания природы и истории формирования Кярдлаской структуры, наиболее важными представляются следующие направления: а) поиски вещественных доказательств природы взрыва, в частности признаков ударного (высокобарического) метаморфизма пород; б) литологический и фациальный анализ заполняющего и перекрывающего комплекса, изучение изменчивости глубины морското бассейна во время средне- и позднеордовикского осадконакопления в разных структурных районах кратера и поиски признаков наличия или отсутствия постумных дифференцированных тектонических движений разных структурных элементов кратера; в) биостратиграфические исследования с целью точной датировки момента взрыва и уточнения истории формирования заполняющего и перекрывающего комплексов; г) поиски признаков отражения кярдласких событий в удалении от самой структуры. 


\section{ЛИТ Е РА Т У А}

Гайлюс Р. П., Мотуза Г. Б., Кала Э. А., Пуура В. А., Сууроя К. А. О кратерообразных структурах Прибалтики. - В кн.: Локальные структуры Белоруссии и Прибалтикн. Вильнюс, 1978, 86-88.

Геология астроблем. Л., 1980.

Импактиты. М., 1981.

Кала Э. А., Пуура В. А., Сууроя К. А. О Кярдлаской кратерообразной структуре на о. Хийумаа. - В кн.: Локальные структуры Белоруссии и Прибалтики. Вильнюс, 1978, 88-91.

Масайтис В. Л. Морфология и глубинное строение земных метеоритных кратеров и астроблем. - Письма в Астрон. ж., 1977, 3, 36-40.

Пуура В. А. Структура южного склона Балтийского щита. Автореф. канд. дис. Таллин, 1974 .

Тектоника Прибалтики. Вильнюс, 1979.

Pirrus, E. Paluküla struktuuri vanusest. - Rmt.: Geoloogiline kogumik, 3, Tallinn, 1976, 83-87.

Viiding, H., Kala, E., Pobul, E. Paluküla mõistatus laheneb. - Eesti Loodus, 1969, 8, $464-474$.

Управление геологии Эстонской ССР

Институт геологии

Академии наук Эстонской ССР
Поступила в редакцию 30/XII 1982

\section{E. KALA, V. PUURA, K. SUUROJA}

\section{KARDLA MATTUNUD KRAATRI EHITUSE POHIJOONED}

Kraatri avastamisele järgnenud 15 aasta jooksul on tema uurimiseks tehtud üle 100 puuraugu ja rakendatud geofüüsikalisi meetodeid. $4-\mathrm{km}$-se läbimõõduga ja $500 \mathrm{~m}$ sügav plahvatuskraater on tekkinud keskordoviitsiumis (kukruse ja idavere ea piiril) ning hiljem mattunud kesk- ja ülemordoviitsiumi setete alla. On kirjeldatud kraatri struktuurilis-litoloogilisi komplekse. Kärdla kraater on üks paremini säilinud seda tüüpi struktuure.

\section{E. KALA, V. PUURA, K. SUUROJA}

\section{MAIN FEATURES OF THE KÄRDLA BURIED CRATER}

After the discovery of the crater 15 years ago, over 100 boreholes have been made and geophysical methods have been applied for its investigation. The crater (diameter $4 \mathrm{~km}$, depth $500 \mathrm{~m}$ ) was formed in the Middle Ordovician. Later it was buried under the Middle and Upper Ordovician beds. The structural-lithological complexes of the crater have been described. The Kärdla crater is one of the best-preserved structures of this type. 